"Expediente promovido por el ministerio del señor fiscal protector general de naturales de esta gran ciudad del Cuzco del Perú, y sus provincias, sobre que se declare por este superior tribunal, una decisión clara, y comprehensiva de todos los protectores partidarios [...]"

Archivo Regional de Cusco. Fondo Real Audiencia del Cusco. Legajo 175, expediente 7, 18 folios, años extremos: $1819-1820$

Carlos Zegarra Moretti

\title{
OpenEdition
}

Journals

Edición electrónica

URL: http://journals.openedition.org/rhj/1308

DOI: $10.4000 /$ rhj.1308

ISSN: 0719-4153

Editor

ACTO Editores Ltda

Referencia electrónica

Carlos Zegarra Moretti, « "Expediente promovido por el ministerio del señor fiscal protector general de naturales de esta gran ciudad del Cuzco del Perú, y sus provincias, sobre que se declare por este superior tribunal, una decisión clara, y comprehensiva de todos los protectores partidarios [...]" », Revista Historia y Justicia [En línea], 10 | 2018, Publicado el 02 mayo 2018, consultado el 15 septiembre 2020. URL : http://journals.openedition.org/rhj/1308 


\section{" EXPEDIENTE PROMOVIDO POR EL MINISTERIO DEL SEÑOR FISCAL PROTECTOR GENERAL DE NATURALES DE ESTA GRAN CIUDAD DEL CUZCO DEL PERÚ, Y SUS PROVINCIAS, SOBRE QUE SE DECLARE POR ESTE SUPERIOR TRIBUNAL, UNA DECISIÓN CLARA, Y COMPREHENSIVA DE TODOS LOS PROTECTORES PARTIDARIOS $[\ldots]^{\prime \prime}$}

\section{ArChivo Regional de Cusco. Fondo Real Audiencia del Cusco. LEGAJO 175, EXPEDIENTE 7, 18 FOLIOS, AÑOS EXTREMOS: $1819-1820$}

Carlos ZEGARRA MORETTI $(*)$

El documento, cuya transcripción paleográfica se da a conocer, permite estudiar la situación de la protectoría de naturales en la Audiencia de Cusco en los últimos años del periodo virreinal. La lectura de este expediente, almacenado en el Archivo Regional de Cusco, en Perú, ayuda a descubrir - por medio de cortos, pero informativos oficios emitidos por los subdelegados de Puno y por el notario de la audiencia- la presencia y problemática de esta institución legal en los partidos que conforman las intendencias de Cusco y Puno en 1819, ad portas de la declaración de independencia de la Corona española ${ }^{1}$.

(*) Magíster en Estudios Americanistas, Universidad de Bonn. Estudiante de Doctorado en Estudios Americanistas, Universidad de Bonn, Alemania. Investigador del Instituto de Pastoral Andina, Perú. investigacion@ipandina.org

\footnotetext{
${ }^{1}$ La Intendencia de Cusco reunía once partidos: Cusco, Aymaraes, Abancay, Chumbivilcas, Chilques y Masques (Paruro), Cotabambas, Calca y Lares, Tinta, Paucartambo, Quispicanchis y Urubamba. Por su parte, la Intendencia de Puno estaba integrada por otras cinco: Azángaro, Carabaya (capital en Crucero), Chucuito, Huancané y Lampa. Véase Fisher, John, El Perú Borbónico 1750-1824, Instituto de Estudios Peruanos, Lima, 2000, p. 305.
} 
Los aspectos recurrentes son el financiamiento de los honorarios del protector partidario y la disponibilidad de personas aptas y residentes en los propios partidos para este cargo. Estos asuntos son discutidos por las autoridades ya mencionadas, allende por el protector partidario de Cusco, Domingo Yépez, y el juez de la caja de censos, el oidor Santiago Corbalán. Sin embargo, son los escritos del fiscal del crimen y protector general de la Audiencia de Cusco, Martín Joseph de Mujica, los que revisten de mayor interés historiográfico.

La fuente aquí glosada constituye una evidencia para afirmar que el destino de esta institución, que fue creada a inicios del periodo virreinal, se encontraba en una etapa de incertidumbre, causando preocupación tanto en instancias metropolitanas como en jurisdicciones locales. Desde la joven Audiencia de Cusco -tribunal creado apenas en 1787se elaboraba una propuesta, la que se suponía, sería evaluada por el rey español. El responsable de la misma, el ya mencionado fiscal Mujica, sugería la implementación de tres medidas (fojas $17 \mathrm{r}-17 \mathrm{v}$ ).

Si bien la primera de estas recomendaciones podía decidirse y aplicarse en el ámbito de la audiencia cusqueña, el resto requería aprobación real. Consciente de esa confirmación peninsular, Mujica termina su exposición suplicando que "estas sus declaraciones interinas" sean elevadas a la corte hispana (foja $18 \mathrm{r})^{2}$.

Una lectura detallada del expediente permite conocer que dichas propuestas no se caracterizaban por su novedad en un plano general o local.

Sin embargo, la postura de Mujica se puede considerar una defensa de la vigencia y necesidad de la protectoría de naturales. Esta actitud supone, a nuestro entender, el intento de Mujica por dotar a la fiscalía criminal de un control más directo y exclusivo sobre la protectoría indiana ${ }^{3}$. Fue él quien se dirigió a los ministros de la audiencia, a raíz del decreto real que suprimía los sueldos para protectores partidarios, asunto considerado por él como un "complicado particular". En ese sentido, sus propuestas se pueden resumir así: mayor independencia para elegir y nombrar protectores partidarios, supervisión constante del desempeño de los mismos, y exigencia de informes a subdelegados y protectores.

\footnotetext{
2 De esta manera, Mujica no se presenta reticente en su intención de entablar un diálogo de forma escrita con el monarca español. El punto de discusión era el decreto real por el cual los protectores partidarios "no deben gozar salario alguno por razon de sus empleos" (foja 1r). Tanto el fiscal como los subdelegados y el protector Yépez se muestran en contra de esta medida. Ello conlleva generar un punto de encuentro - a distancia- entre autoridades de la audiencia -en este caso, el fiscal, cuya voz representa, asimismo, la de un sector de funcionarios- y el rey hispano.

${ }^{3}$ Según lo hasta ahora investigado, y teniendo en cuenta las trayectorias de los fiscales anteriores que ejercieron en Cusco -Antonio Suárez, Luis Gonzalo del Río, Bartolomé Bedoya-, Mujica sería el único con experiencia previa en defensa legal indígena. Véase Zegarra Moretti, Carlos, "Defensa jurídica durante la Audiencia de Cusco: instituciones durante el periodo Tardío virreinal", ponencia presentada en el simposio "Historia Colonial", VII Congreso Nacional de Historia. Trujillo, 2016, p. 14.
} 
Asimismo, Mujica descarta algunas soluciones, como que los subdelegados nombraran "protectores efímeros" o la realización de procedimientos verbales. El significativo desorden en el manejo de la institución de la protectoría, que encontró cuando comenzó a desempeñarse allí, debió de convencerlo en dicha postura: la fiscalía no disponía de datos certeros -ni, incluso, los mismos subdelegados, tal fue el caso del de Chucuito- sobre el número de protectores partidarios activos, el salario percibido ni la validez de su nombramiento 4 .

Estos esfuerzos pueden considerarse atisbos de una maduración institucional de la audiencia cusqueña. Sin embargo, no llegaron a florecer, ya que la actitud de la Corona hacia la protectoría no cambió de rumbo. El monarca español, al eliminar los sueldos de los defensores, tal vez estaba dando un paso hacia una política, que concluiría en la supresión total de los protectores partidarios en $1824^{5}$.

La riqueza de los textos de Mujica se debe, también, a que en ellos se pueden encontrar variadas reflexiones sobre la institución jurídica comentada. Por ejemplo, en un momento se cuestiona si, teniendo en cuenta la total inserción del indígena en el mundo legal, sería mejor "suspenderle los privilegios de menor, con que nuestro Derecho y práctica municipal ha tenido y tiene por conveniente agraciarlo" (foja 12r). Esta consideración reconoce al indígena como un sujeto jurídico activo en diferentes procedimientos legales civiles (foja 12r), que trasciende la visión del indígena meramente "pleitista"6.

\footnotetext{
${ }^{4}$ Mujica, para informarse de la existencia de protectores en la Intendencia de Cusco, consultó al escribano de cámara de la audiencia, Mariano de Ojeda y Venero; él le informó de la existencia de protectores partidarios en Cusco y Paruro (foja $7 \mathrm{r}$ ). No obstante, Mujica comprendió que la información recabada es limitante. Señala que "por casualidad" descubrió la existencia de abogados protectores en Paucartambo y Cotahuasi, "aunque sin conocimiento de sus nominadores ni algun otro especifico claro" (foja 11r-11v). Esto nos debe llevar a pensar en el funcionamiento consuetudinario del sistema de defensa legal indígena en los partidos. Esta idea es reforzada en el hecho de que, en Chucuito, según su subdelegado, el protector activo Melchor Aragón no residía en la capital del partido, sino en Ilave, un pueblo cercano, ocasionando el nombramiento de defensores provisionales (foja 8r). Asimismo, de forma muy breve, se puede resaltar la vigencia de los quelqueres, a los cuales, de acuerdo con el subdelegado de Carabaya, Manuel Antonio de Gómez, "suelen pagar los Indios por sus escritos". Este término de origen aimara es traducido por Mujica como "pendolistas" (fojas 9r y 16r). La vinculación de este actor con los "quilcaycamayoc", o "escribanos de naturales, es inevitable. Véase Burns, Kathryn, "Making Indigenous Archive. The Quilcaycamayoc of Colonial Cuzco" en Ramos, Gabriela \& Yannakakis, Yanna (ed.), Indigenous Intellectuals: Knowledge, Power, and Colonial Culture in Mexico and the Andes, Duke University Press, Durham; Londres, 2014, p. 238.

${ }^{5}$ Archivo Regional de Cusco (ARC), Real Audiencia (RA), Legajo (L) 180, Expediente (E) 18, Foja (f) 1r.

${ }^{6}$ Sobre el pleitismo en los indígenas, véanse: Borah, Woodrow, El Juzgado General de Indios en la Nueva España, Fondo de Cultura Económica, México D. F., 1970, p. 132; Pease, Franklin, “¿Por qué los andinos son acusados de litigiosos?” en Borghi, Marco (ed.), Derechos culturales, Pontificia Universidad Católica del Perú, Universidad de Friburgo, Lima, 1996, p. 27-37; Poloni-Simard, Jacques, "Los indios ante la justicia. El pleito como parte de la consolidación de la sociedad colonial" en Lavallé, Bernard (ed.), Máscaras, tretas y rodeos del discurso colonial en los Andes, Instituto Francés de Estudios Andinos, Instituto Riva Agüero, Lima, 2005, p. 182; De la Puente Brunke, José, "La Audiencia de Lima y la 'protección de los naturales' (siglo XVII)" en Soberanes Fernández, José Luis \& Martínez de Codes, Rosa María, Homenaje a Alberto de
} 
Ello no significa que Mujica estuviese contradiciendo la "miserabilidad" del indígena7. En sus palabras, éste sigue siendo un "menor", debido al "servil encogimiento" que experimenta al estar frente a la autoridad judicial, y por "la fastidiosa torpesa con que generalmente se explican" (foja 11r).

Las ventajas de la existencia de la protectoría se dirigen, en las ideas de Mujica, a los indígenas, ya que sin ésta, o los indios "callan los enormes agravios que reciben" o "han de salir ordinariamente de sus residencias en busca de pendolistas" (foja 11v) ${ }^{8}$. También se encuentran, en sus páginas, alegatos en contra de alternativas, como los juicios verbales y los ya evocados "protectores provisionales" (fojas $11 \mathrm{v}$ y $12 \mathrm{r}$ ).

Pero, ¿quién era Mujica? Era peninsular, nacido en 1774; a los 15 años viajó a América, y fue a residir en Cusco, en 1794, para estudiar en la Universidad San Antonio Abad. Fue admitido como abogado, en enero de 1802, en la Audiencia de Lima9. De su hoja de servicios destaca su designación, en 1804, en el puesto de protector substituto de Huamanga, el que asumió en propiedad en el año 1812. Su desempeño es valorado positivamente, afirmándose que "lejos de haber exigido derechos algunos á los indios, se gravó con el coste de papel y amanuenses y no realizó muchas ideas benéficas por la total indotación del empleo". Tomó posesión efectiva del cargo de fiscal del crimen de la Audiencia de Cusco en $1817^{10}$.

la Hera, Universidad Nacional Autónoma de México, México D. F., 2008, p. 662; y Saravia Salazar, Javier Iván, Los Miserables y el Protector. Evolución de la protectoria [sic] de indios en el Virreinato peruano. Siglos XVI-XVIII, Tesis de Licenciatura en Historia, Universidad Nacional Mayor de San Marcos, Lima, Perú, 2012, p. 122-130.

${ }^{7}$ La producción historiográfica sobre la "miserabilidad del indígena" y sus consecuentes privilegios es larga, variada y suele centrarse en su implementación en los años iniciales de la presencia hispana en América. Por ejemplo, véanse: Bayle, Constantino, El protector de indios, Consejo Superior de Investigaciones Científicas, Sevilla, 1945, 175 p.; Castañeda, Paulino, "La condición miserable del indio y sus privilegios", Anuario de Estudios Americanos, Sevilla, tomo XXVIII, 1971, p. 245-355; Duve, Thomas, "La condición jurídica del indio y su condición como persona miserabilis en el Derecho Indiano" en Losano, Mario (ed.), Un giudice e due leggi. Pluralismo normativo e conflitti agrari in Sud America, Giuffre, Milan, 2004, p. 3-33; y Cunill, Caroline, "El indio miserable: nacimiento de la teoría legal en la América colonial del siglo XVI", Cuadernos inter.c.a.mbio, San José, vol. 8, n9, 2011, p. 229-248.

8 Causas judiciales incoadas por comunidades indígenas ante la Audiencia de Cusco, tras el levantamiento de Túpac Amaru, han sido estudiadas, entre otros, por Cahill, David, "Repartos ilícitos y familias principales en el sur andino: 17801824", Revista de Indias, Madrid, vol. 48, n¹82-183, 1988, p. 465-472; Walker, Charles, "La violencia y el sistema legal: los indios y el Estado en el Cusco después de la rebelión de Tupac Amaru" en Urbano, Henrique \& Lauer, Mirko (ed.), Poder y violencia en los Andes, Centro de Estudios Regionales Andinos "Bartolomé de Las Casas", Cusco, 1991, p. 125-147; y por Garrett, David, Sombras del Imperio. La nobleza indigena del Cuzcco, 1750-1825, Instituto de Estudios Peruanos, Lima, 2009.

${ }^{9}$ Véanse: Burkholder, Mark A. \& Chandler, D. S., Biographical Dictionary of Audiencia Ministers in the Americas, 1687-1821, Greenwood Press, Westport, Londres, 1982, p. 231; Archivo General de Indias (AGI), Cuzco (C), Legajo (L) 4, Relación de los méritos y servicios del doctor don Martín José de Muxica, Fojas (f) 1r-1v; Archivo General de Indias (AGI), Cuzco (C), Legajo (L) 4, Estado de la Real Audiencia de Cuzco, Foja (f) 2r.

${ }^{10}$ Burkholder, M. A. \& Chandler, D. S., Biographical Dictionary, Op. Cit., p. 231; Archivo General de Indias (AGI), Cuzco (C), Legajo (L) 4, Relación de los méritos y servicios del doctor don Martín José de Muxica, Foja (f) 2r. 
La experiencia en el cargo de protector, pero también el conocimiento de la situación local, gracias a los informes recopilados y de las disposiciones reales, hacen de Mujica una voz autorizada en el tema.

En conclusión, este documento constituye un hito mayúsculo en la historia de la protectoría de naturales en el virreinato del Perú, la cual suscitó discusiones hasta las postrimerías virreinales. Análisis más profundos dirigidos al desarrollo de esta institución en espacios locales - a nivel de la Audiencia de Cusco, pero, además, a nivel de los partidospermitirán conocer el significado real que tuvo dentro del sistema jurídico indígena ${ }^{11}$.

\section{Documentación de archivo}

Archivo General de Indias, Sevilla, España, Fondo Cuzco, Legajo 4.

Archivo Regional de Cusco, Cusco, Perú, Fondo Real Audiencia, Legajos 175 y 180.

\section{Bibliografía}

Bayle, Constantino, El protector de indios, Consejo Superior de Investigaciones Científicas, Sevilla, 1945, 175 p. Borah, Woodrow, El Juggado General de Indios en la Nueva España, Fondo de Cultura Económica, México D. F., 1970, 488 p.

Burkholder, Mark A. \& Chandler, D. S., Biographical Dictionary of Audiencia Ministers in the Americas, 1687-1821, Greenwood Press, Westport, Londres, 1982, 494 p.

Burns, Kathryn, "Making Indigenous Archive. The Quilcaycamayoc of Colonial Cuzco" en Ramos, Gabriela \& Yannakakis, Yanna (ed.), Indigenous Intellectuals: Knowledge, Power, and Colonial Culture in Mexico and the Andes, Duke University Press, Durham, Londres, 2014, p. 237-260.

Cahill, David, "Repartos ilícitos y familias principales en el sur andino: 1780-1824", Revista de Indias, Madrid, vol. XLVIII, n¹82-183, 1988, p. 465-472.

Castañeda, Paulino, "La condición miserable del indio y sus privilegios", Anuario de Estudios Americanos, Sevilla, tomo XXVIII, 1971, p. 245-355.

Cunill, Caroline, "El indio miserable: nacimiento de la teoría legal en la América colonial del siglo XVI", Cuadernos inter.c.a.mbio, San José, vol. 8, n9, 2011, p. 229-248.

Cutter, Charles R., The Protector de Indios in Colonial New Mexico, 1659-1821, University of New Mexico Press, Alburqueque, 1986, 129 p.

\footnotetext{
${ }^{11}$ Para el caso peruano, los estudios más resaltantes sobre esta institución se han centrado en los primeros dos siglos de la etapa virreinal y priorizando la Audiencia de Lima. Véanse: Ruigómez Gómez, Carmen, Una política indigenista en los Habsburgo: el protector de indios, Ediciones de Cultura Hispánica, Madrid, 1988, 227 p.; Novoa, Mauricio, The Protectors of Indians in the Royal Audience of Lima: History, Careers and Legal Culture, 1575-1775, Nijhoff, Brill, Leiden, Boston, 2016, 325 p.; Saravia Salazar, J. I., Los Miserables y el Protector, Op. Cit. En un ámbito americano se debe mencionar, principalmente, las obras de Cutter, Charles R., The Protector de Indios in Colonial New Mexico, 1659-1821, University of New Mexico Press, Alburqueque, 1986, 129 p.; Borah, W., El Juzgado General de Indios, Op. Cit.; y Bonnett, Diana, Los protectores de naturales en la Audiencia de Quito: siglos XVII y XVIII, Abya Yala, Quito, 1992, 153 p.
} 
De la Puente Brunke, José, “La Audiencia de Lima y la 'protección de los naturales’ (siglo XVII)” en Soberanes Fernández, José Luis \& Martínez de Codes, Rosa María, Homenaje a Alberto de la Hera, Universidad Nacional Autónoma de México, México D. F., 2008, p. 659-678.

Duve, Thomas, "La condición jurídica del indio y su condición como persona miserabilis en el Derecho Indiano" en Losano, Mario G. (ed.), Un giudice e due leggi. Pluralismo normativo e conflitti agrari in Sud America, Giuffre, Milan, 2004, p. 3-33.

Fisher, John, El Perú Borbónico 1750-1824, Instituto de Estudios Peruanos, Lima, 2000, 359 p.

Garrett, David, Sombras del Imperio. La nobleza indígena del Cuzco, 1750-1825, Instituto de Estudios Peruanos, Lima, 2009, 450 p.

Novoa, Mauricio, The Protectors of Indians in the Royal Audience of Lima: History, Careers and Legal Culture, 15751775, Nijhoff, Brill, Leiden, Boston, 2016, 325 p.

Pease, Franklin, “PPor qué los andinos son acusados de litigiosos?” en Borghi, Marco (ed.), Derechos culturales, Pontificia Universidad Católica del Perú, Universidad de Friburgo, Lima, 1996, p. 27-37.

Poloni-Simard, Jacques, "Los indios ante la justicia. El pleito como parte de la consolidación de la sociedad colonial" en Lavallé, Bernard (ed.), Máscaras, tretas y rodeos del discurso colonial en los Andes, Instituto Francés de Estudios Andinos, Instituto Riva Agüero, Lima, 2005, p. 177-188.

Ruigómez Gómez, Carmen, Una política indigenista en los Habsburgo: el protector de indios, Ediciones de Cultura Hispánica, Madrid, 1988, 227 p.

Saravia Salazar, Javier Iván, Los Miserables y el Protector. Evolución de la protectoria [sic] de indios en el Virreinato peruano. Siglos XVI-XVIII, Tesis de Licenciatura en Historia, Universidad Nacional Mayor de San Marcos, Lima, Perú, 2012, 375 p.

Walker, Charles, "La violencia y el sistema legal: los indios y el Estado en el Cusco después de la rebelión de Tupac Amaru” en Urbano, Henrique \& Lauer, Mirko (ed.), Poder y violencia en los Andes, Centro de Estudios Regionales Andinos "Bartolomé de Las Casas”, Cusco, 1991, p. 125-147.

Zegarra Moretti, Carlos, "Defensa jurídica durante la Audiencia de Cusco: instituciones durante el periodo Tardío virreinal", ponencia presentada en el simposio "Historia Colonial", VII Congreso Nacional de Historia, Trujillo, Perú, 2016, 15 p.

Se agradece la autorización del director del Archivo Regional de Cusco, Licenciado Carlos O. Ojeda Olivera, para la difusión y descarga de las $\mathrm{f}$ otografías del documento aquí comentado y transcrito.

Notas del autor:

(1) La transcripción se ha realizado agrupando el contenido en folios. Las abreviaturas han sido desarrolladas entre corchetes

(2) Se emplea la abreviatura siguiente : Archivo Regional de Cusco (ARC), Real Audiencia (RA), Legajo (L) 175, Expediente (E) 7, foja (f) r/v. 


\section{Revista Historia y Justicia}

ISSN 0719-4153 revista.historiayjusticia.org N¹0 - Santiago de Chile, abril 2018, p. 241-280

//carátula//

Febrero 9. de 1819.

$\mathrm{N} 12$. Expediente promovido por el ministerio del Señor Fiscal de S[u] M[ajestad] Protector General de Naturales de esta gran Ciudad del Cuzco del Perú, y sus Provincias, sobre que se declare por este superior Tribunal, una decicion clara, y comprehensiva de todos los Protectores partidarios, creados, y que se crearen en el distrito de esta real Audiencia, para que se sirva de regla acerca de los derechos que deban llevar en las causas de Yndios á los Caciques y Comunidades.

$\mathrm{R}[\mathrm{ea}] \mathrm{l}$ Acuerdo

ARC, RA, L 175, E 7, carátula 
//F. $1 \mathrm{r} / /$

El REY= Por cuanto en carta de 24 de Febrero de 1779 me hizo presente D[o]n Ysidro Peralta, Gobernador y Capitan General de la Isla Española, y ciudad de Santo Domingo, que las facultades con que su antecesor D[o]n Joseph Solano habia procedido á la confirmacion del nombramiento que hizo á favor de D[o]n Juan Pablo Mantilla, de Protector de Indios de la Provincia de Venezuela, eran en su concepto las mismas que para semejantes casos le permitia la ley $1^{\mathrm{a}}$. del tit[ulo] y lib[ro] $6^{\circ}$. de la Recopilacion de mis Reynos de las Indias, suplicándome que en esta atencion fuese servido de continuarle la misma regalía, como anexa al empleo que obtenia. Visto lo referido en mi consejo de las Indias, con lo que en su inteligencia expuso mi fiscal, y consultandome sobre ello en 18 de agosto del año próximo pasado, he resuelto declarar, como declaro, que la eleccion y nombramiento de Jueces, ó Protectores Partidarios de Indios de los respectivos distritos de aquellos mis dominios, corresponde privativamente á los fiscales criminales de las Audiencias de ellos, y no á sus Presidentes ó Gobernadores, en conformidad de la facultad que les estaba declarada en sus títulos á los Protectores fiscales de las Audiencias, cuyas funciones se hallan en el dia refundidas en los Fiscales Criminales, á consecuencia del nuevo metodo de gobierno que tube á bien establecer en ellas, por mi Real Decreto expedido en el Pardo en 11 de marzo de 1776; y asi mismo: he venido en declarar, que los expresados Protectores Partidarios no deben gozar salario alguno por razon de sus empleos; que su nombramiento se verifique solo en los Partidos donde hasta ahora haya sido costumbre haberlos, ó se reconociese urgente necesidad de establecerlos de nuevo, calificada indispensablemente por el Presidente, Regente, y Oidores de la Audiencia á quien corresponda; y últimamente que los nominados fiscales criminales hayan de dar cuenta a sus respectivas Audiencias de las personas que eligieren para estos encargos Subal-

ARC, RA, L 175, E 7, f 1r 
//F. 1v//

ternos. Por tanto ordeno y mando á los Presidentes Regentes y Oidores de las expresadas mis Audiencias de los Reynos de las Indias y á los fiscales criminales de ellas, guarden cumplan y egecuten en la parte que á cada uno corresponde la enunciada mi Real Resolucion, segun y en la forma que va expresada, por ser asi mi voluntad. Fecha en el Pardo á 11 de marso de 1781= YO EL REY= Por mandado del Rey Nuestro Señor= Miguel de San Martin Cueto.

"En consecuencia del Oficio de V[uestra] S[eñoria] de 25 de julio último, le incluyo copia de la Real cédula de 11 de marzo de 781, relativa á la facultad de los fiscales del crimen para nombrar los Protectores Partidarios en las Provincias del Distrito de la Audiencia respectiva con las prevenciones que en ella se enuncian: quedandome la satisfaccion de haber desempeñado el encargo de V[uestra] S[eñoría], como lo egecutaré gustoso en todo lo que pueda ocurrir en lo sucesivo. Dios guarde á V[uestra] S[eñoria] muchos años. Lima agosto 10 de 1818= Joseph de Yrigoyen= Señor fiscal Protector General de la Real Audiencia del Cuzco."

Son copias exactas.

Mugica [rúbrica]

[Folio en blanco sin enumeración]

ARC, RA, L 175, E 7, f 1v 
//F. 2r//

Cuzco y Feb[re]ro 9 de 1819.

Por resivido, pasese al

R[eal] Acuerdo.

[tres firmas]
$\mathrm{M}$ [uy] P[oderoso] S[eñor]

La ley $3^{\text {a }}$. del título de los Protectores de Indios manda que en las Ciudades donde hubiere Audiencia se elija un Letrado que defienda á los Indios y siga sus pleitos, asalariado en penas de Estrados, ó en bienes de comunidad, donde no hubiera especial consignacion, prohibiendole llevar derechos en ningun caso bajo de graves penas al arbitrio de los Gefes.

Este letrado es aquí el Protector partidario de Naturales; mas declarando S[u] M[ajestad] en la Real Cédula de 11 de marzo de 1781, la cual presento á V[uestra] Alteza] en copia legal, que los Protectores partidarios no deben gozar salario alguno por razon de sus empleos: yo dudo; si al menos podrán llevar medios derechos á los Caciques y comunidades, ya que no deban llevarlos á los Indios particulares, como parece que lo ha dispuesto V[uestra] A[udiencia] respecto del Procurador?

Si los llevan, se quebranta la ley, que no hace distincion alguna; y en cuya conformidad la Protectoría general de Lima previene á los Subalternos partidarios en sus Títulos, que no podrán llevar derechos á los Indios, exigir gratificaciones, admitir servicios ni regalo alguno de ellos. Y si no los llevan, ni tampoco gozan de ningun salario ¿quién es el Abogado que querrá

ARC, RA, L 175, E 7, f 2r 
/F. 2v//

encargarse de la Protectoría partidaria, ó que encargandose de ella, la desempeñará al colmo de los deseos Soberanos y de las necesidades de los Indios?

Yo serví en Guamanga muchos años este destino sin la mas minima gratificacion de ninguna clase, y antes bien pensionalmente en algunos reales; pero tambien es verdad que se me hacia muy doloroso este sacrificio, que al cabo de tiempos pretendi alguna asignacion aunque sin fruto, $y$ que probablemente me habia expedido mejor y con mas gusto si la hubiera logrado: no siendo menos cierto, que si entonces influían en mi el pundonor, la idea de labrar merito, la esperanza de que se me recompensaría algun dia, segun se me ha recompensado con exceso, ú otras consideraciones de este carácter; los mas de los hombres se mueven al trabajo por, y en razon directa de algun interes físico, actual, seguro y libre de contingencias.

Por esto es, que sin embargo de haberseme denunciado muchas veces, que el Lic[enciado] D[o]n Domingo Yepes, quien hace hoy de Protector Partidario en la ciudad, exige derechos á los Indios; pareciendome poco menos que imposible encontrar en el Cuzco otro Letrado que los sirva enteramente de valde, no he tenido resolucion de prohibirselo abiertamente, contentandome solo con aconsejárselo y encargarle la conciencia, que desde luego se la juzgo bastante delicada. Pero como esto no satisfaga de lleno á la mia, ni al respeto que me merecen las leyes; deseoso de ponerme á cubierto de toda responsabilidad ante Dios y ante los hombres, imploro de las Superiores

ARC, RA, L 175, E 7, f 2v 
//F. 3r//

luces de V[uestra] A[lteza] una decision terminante, clara y comprehensiva de todos los Protectores partidario creados, y que se crearen en el distrito de esta Real Audiencia, la cual me sirva de regla en este complicado particular.

Dios gu[ard]e á V[uestra] A[lteza] m[ucho]s añ[os]s Cuzco 9 de febrero de 1819.

\author{
M[uy] P[oderoso] S[eñor]
}

Martin J[ose]ph de Mugica [rúbrica]

Al Rey N[ues]tro Señor en esta su

Real Audiencia y Chancilleria.\}

ARC, RA, L 175, E 7, f 3r 
//F. 3v//

Cuzco y F[e]br[er]o 11 de 1819.

$\underline{S}$ [eñores] Visto en real Acuerdo con asistencia del S[eñ]or Fiscal

Reg[en]te mandaron los S[eñores] del margen dar traslado al

Corbalan Protect[o]r de Naturales, $\mathrm{p}$ [ara] q[ue] lo conteste dentro del

Darcourt termino Ordinario.

[tres firmas]

Proveyeron, y rubricaron en

ARC, RA, L 175, E 7, f 3v 
//F. $4 \mathrm{r} / /$

en el oficio que antecede en el dia, mes, y año de su fecha, los Señores Don Pedro Antonio Cernadas, Bermudez de Castro, del Consejo de su Magestad, en el supremo de Yndias, Caballero de la real y distinguida orden española de Carlos tercero, Don Santiago Corbalan, y Don José Darcourt y Carta Caballero de la Cruz y Placa, en el real y militar or[de]n de San Hermengildo, igualmente del Consejo de S[u] M[ajestad] Regente, y Oydores de esta real Audiencia, de que certifico.

\section{Venero [rúbrica]}

En la Ciudad del Cuzco, en doce dias del mes de Febrero de mil ochocientos dies y nueve: Yo el Escribano de Camara, hice saber el anterior decreto al Licenciado Don Eugenio Domingo de Yepez Abogado de esta real Audiencia Protector Partidario de Naturales de ella, en su persona, de que certifico.
Yepes [rúbrica]
Venero [rúbrica]

ARC, RA, L 175, E 7, f 4r

[//F. 4v// en blanco] 
//F. $5 \mathrm{r} / /$

Contesta, y al otro si pide providencia.

\section{$\mathrm{M}[u y] \mathrm{P}[$ oderoso] S[eñor]}

El Protector Partidario de Naturales ante V[uestra] A[lteza] conforme á d[e]r[ech]o contestando al anterior traslado consiguiente al oficio de vuestro Fiscal del crimen en el que solicita una resolucion terminante acerca de los d[e]r[ech]os que deban llebar los Protectores Partidarios ó salario que deban gozar y lo demas deducido, dice: Que $\mathrm{V}$ [uestra] A[lteza] tiene bien penetrado por larga experiencia lo pesado que es este empleo por las diarias y casi continuas ocurrencias que tiene que expedir el Protector sin mas recompensa á las veces que la futura esperanza: porque aunque es verdad que algunos Yndios Casiques y comunidades pagan medios derechos en conformidad á lo que $\mathrm{V}$ [uestra] A[lteza] tiene mandado en las muchas tasaciones de costas que han ocurrido en vuestra Secretaria; pero tambien es cierto que estos cortos emolumtos ${ }^{\circ}$ [sic: emolumentos] nunca han compensado ni pueden compensar el trabajo continuo del Protector, no menos que las penosas tareas y comprometimientos de oficio á que lo inducen su empleo. Por ello seguro el que habla de que V[uestra] A[lteza] no dejara indotada esta Plaza tanto mas delicada quanto laboriosa para un pobre Letrado que no tiene otra subcistencia que el ingreso de su oficio, el que, aun no lo puedo expedir preocupado con esta confianza que se ha dignado hacer en mi debilidad: ocurro á su Soberania reproduciendo los mismos escollos que indica el Señor Fiscal; se sirva tomar un medio el mas ventajoso y equitativo que sirva de alivio á los Yndios, y de estimulo á la Protectoria para su mejor contraccion, qual el de una competente Dotacion que pueda compensar el trabajo conforme á la Ley citada por d[ic]ho Señor Fiscal, siempre que esta tenga su obcervancia: y en el caso de no haber lugar se prefixe el tiempo que deba uno exercer el empleo, con la seguridad de que cumplido él, tenga seguro ascenso á otro

ARC, RA, L 175, E 7, f 5r 
$/ / \mathrm{F} .5 \mathrm{v} / /$

de alguna Dotacion, y sea este cierto y determinado por V[uestra] A[lteza] Por tanto y habiendo por contestado $=$

A V[uestra] A[lteza] pide y suplica asi lo provea y mande como lleva expuesto que es justicia y para ello. \&a.

Otro si dice: Que debiendo ser de la incumbencia de la Protectoria la defenza de la Caxa de Censos de Yndios; se ha de servir V[uestra] A[lteza] igualmente declarar sea en el caso que se fuese, deber entenderse su expedicion con el que habla, asi para que goce del corto emolumento que tiene, como para que sirva de regla en todo tiempo. Que es Just[ici]a Ut supra.

\section{Domingo de Yepes [rúbrica]}

Cuzco y Feb[re]ro 26 de 1819.

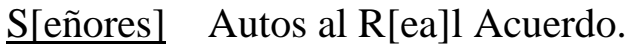

Reg[en]te

Corbalan

Darcourt. [tres firmas]

Venero [rúbrica]

En la Ciudad del Cuzco, en veinte y seis de Febrero de mil ochocientos dies y nueve: Yo el Escribano interino de Cámara, hice presente el anterior decreto al Señor Don Martín Joseph de Mugica del Consejo de su Magestad Fiscal del crimen de esta real audiencia, estando su Señoria en su estudio, en la casa de su morada, de que certifico.

Venero [rúbrica]

Cuzco y Marzo 4 de 1819.

S[eñores] Y vistos en R[ea]l Acuerdo: pasese este exped[ien]te al S[eñ]or juez de la Caxa de Reg[en]te Sensos, p[ara] que informe sobre el otro si lo q[ue] le paresca combeniente, y a su Corbalan $\mathrm{t}[\mathrm{iem}]$ po se proberá sobre todo.

Darcourt [tres firmas]

Venero [rúbrica]

ARC, RA, L 175, E 7, f 5v 


\section{Revista Historia y Justicia}

//F. $6 \mathrm{r} / /$

$$
\text { M[uy] P[oderoso] S[eñor] }
$$

El Oydor Jues privativo de la Caja gen[era]l de Censos de esta Capital y su Provincia cumpliendo con el Ynforme que se le ha mandado producir por V[uestra] A[lteza] en Auto de 4, del corr[ien]te sobre la solicitud entablada por el Abog[a]do d[o]n Dom[ing]o Yepez como Protector Partidario de Naturales en el Otro sí de su Escrito de f[oja] 5, b[uel]ta dice; que por el Articulo $3^{\circ}$, de las Ordenansas formadas para el gov[ier]no y arreglo de la Caja de Censos, está designado por unico Defensor de ella el s[eñ]or Fiscal Protector G[ene]ral con la ayuda de costa de docientos $\mathrm{p}[\mathrm{eso}] \mathrm{s}$ por año, y por su auxiliar el Agente Fiscal con la dotacion de ciento sinq[uen]ta $\mathrm{p}$ [eso]s tambien por año: Por lo tanto cree el Jues de la Caja, que no es facil hacer variacion alguna sobre el particular; porque desde luego se entraria en un litigio con el Agente Fiscal por el d[e]r[ech]o adquirido que tiene á este sobresueldo: En cuya conseq[uenci]a opina el que Informa no ser asequible la solicitud de Yepez, y sobre que V[uestra] A[lteza] deber minará lo que le paresca mas en Just[ici]a Cuzco M[a]r[z]o 6, de 1819,

Santiago Corbalan [rúbrica]

ARC, RA, L 175, E 7, f 6r 
//F. 6v//

Cuzco Marso 6 de 1819.

S[eñores] Autos $\mathrm{p}[\mathrm{o}] \mathrm{r}$ el relator al R[eal] Acuerdo.

Reg[en]te [dos firmas]

Darcourt

Jordan [rúbrica]

Cuzco y Marzo 8 de 1819.

S[eñores] $\mathrm{Y}$ vistos, con los antecedentes $\mathrm{q}[\mathrm{u}] \mathrm{e}$ se han traido a la vista;

Reg[en]te buelban de la del S[eño]r Fiscal=

Corbalan [tres firmas]

Darcourt

Jordan [rúbrica]

ARC, RA, L 175, E 7, f 6v 
$/ / \mathrm{F} .7 \mathrm{r} / /$

Copia.

A.

Satisfago al que V[uestra] S[eñoría] se ha servido dirigirme en 15 del que corre, preceptuándome que en contestacion le diga cuantos Protectores Partidarios de naturales hay en toda esta Provincia y en la de Puno \&c.

Desde que he tenido el honor de servir esta Escribanía de Cámara en calidad de Escribano, no he visto nombrar á sugeto alguno de Protector Partidario en toda la Provincia de la comprehension de esta Real Audiencia ni en la de Puno, á excepcion de d[o]n J[ose]ph Vega, vecino del pueblo de Guanuquite en el Partido de Paruro, cuyo expediente acompaño; por lo que estoy en la firme creencia de que no habrá en ningun Partido Protector nombrado.

El que en esta ciudad actualmente egerce este empleo, que es el Lic[enciado] D[o]n Domingo de Yepes, repentinamente ha salido apersonandose como tal Protector; mas no sé con qué título ó porque concesión, pues ante mi no se le ha extendido su nombramiento, ni aun se le ha juramentado.

Por los seis expedientes que acompaño, que en tiempos anteriores, se habian organizado, verá V[uestra] S[eñoria] la fórmula que los Señores Fiscales sus antecesores usaron en los títulos que en su ves expidieron.

Es cuanto debo exponer sobre este particular en obsequio de lo que V[uestra] S[eñoría] me ordena.

Dios guarde á V[uestra] S[eñoria] muchos años. Cusco setiembre 17 de $1818=\mathrm{D}[\mathrm{o}] \mathrm{n}$ Mariano de Ogeda y Venero = S[eño]r fiscal de S[u] M[ajestad $]$ $\mathrm{D}[\mathrm{o}] \mathrm{r}$ D[o]n Martin J[ose]ph Mugica=

Es copia del original que existe en mi poder. Cusco 9, de diciembre de 1819.

Mugica [rúbrica]

ARC, RA, L 175, E 7, f 7r

[//F. 7v// en blanco] 
B.

Copia En cumplimiento de la Superior or[de]n de lo del corriente, en la q[ue] se sirve V[uestra] S[eñoria] transcribirme el oficio del S[eño]r Fiscal Protector g[ene]ral de la Real Audiencia del Distrito, puedo afirmar q[ue] en todo el Partido de mi cargo no hay un Protector nombrado, ni persona q[ue] pueda ejercer dicho empleo excepto el de esta Capital, unico q[ue] desempeña en los recursos dirigidos al Gobierno= Dios gu[ard]e a V[uestra] S[eñoría] muchos años. Puno noviembre 24 de 1818= Mariano de Caceres= S[eño]r Gob[ernad]or Intend[en]te de la Provincia $\mathrm{D}$ [on] Tadeo Joaquin de Garate.

Otra He recivido el oficio en q[ue] con fecha 20 del corriente me transcribe V[uestra] S[eñoría], y q[ue] con la de 6 del mismo le ha dirigido el S[eño]r fiscal de la Real Audiencia del Distrito, relativo á $\mathrm{q}[\mathrm{ue}]$ se informe en orden a los puntos q[ue] en él se expresan: Y cumpliendo $\mathrm{p}[\mathrm{o}] \mathrm{r}$ mi parte con el q[ue] segun lo en su consecuencia mandado p[o]r V[uestra] S[eñoría] debo expedir; lo q[ue] puedo informar es lo siguiente $=$ Que en el pueblo de Ilave, comprehension de esta Provincia, reside el Protector partidario denominado D[o]n Melchor Aragon, á quien á mi ingreso al mando de este Partido, encontré sirviendo el empleo, sin saber todavia con que nombramiento ejerce su ministerio, hasta averiguarlo en estos dias para satisfacer á V[uestra] S[eñoría] con exactitud: que ha desempeñado y desempeña en lo poco que se ofrece expedir con puntualidad, aunque con motivo de no residir en la Capital, las mas veces me veo obligado á nombrar el que ha de servir de tal para la prosecucion de causas criminales que se presentan: que ignoro el sueldo y ovenciones que persibe de su oficio: que no hay necesidad de aumentarlos porque serían gravosos á los Indios tributarios, fomentándoles pleitos, y ocasionándoles con este motivo exacciones. Pero que aun estando se tratase de aumentarlos, se hallan tan escasos de vecinos Españoles y racionales los Pueblos, que no encontraría persona idónea en quien ponerse para un encargo semejante; pues se carece de un individuo á quien se le pueda comisionar una Sumaria; y mucho menos entre los Indios que no hay uno que sepa ordenar una oracion en un memorial: siendo cuanto puedo informar á V[uestra] S[eñoría] sobre el particular= Dios gu[ard]e á V[uestra] S[eñoría] muchos años. Chucuito y noviembre 25 de 1818= Francisco de Paula Mendizabal= S[eño]r Gob[ernad]or Intendente $\mathrm{D}[\mathrm{o}] \mathrm{n}$ Tadeo Garate.

Otra En cumplimiento de lo prevenido por V[uestra] S[eñoría] en Decreto 20 del corriente dictado á continuacion del oficio del S[eño]r fiscal de la Real Audiencia del Distrito, que uno y otro tenor se sirve transcribirme en el de la misma fecha, debo hacer presente á V[uestra] S[eñoría] que en oficio de 18 de noviembre del año pasado de 1817, expuse la necesidad que habia de un Protector de Naturales en este Partido, y como en decreto de 24 del mismo mes, ordenó V[uestra] S[eñoría] que por esta Subdelegacion, se nombrase interinamente un Protector que entendiese en los asuntos de los Indios, segun persuade la copia que acompaño, se nombró por tal Protector interino á D[on] Domingo Molina, quien estuvo desempeñando el cargo hasta mediados del corriente, y con motivo de haberse retirado de este Partido se halla él, en el dia carente del insinuado Empleado. Por ello y con respecto á lo que previene el referido S[eño]r fiscal, me parece que es llegado el caso de que se le proponga para la propiedad una persona de las cualidades que expresa en su oficio $=$ La dotacion de la Protectoría es casi ninguna, porque no hay rentas conocidas de que asignarle un competente sueldo, y sería muy conveniente que de los bienes de comunidad se le señalase al Protector un salario por el cual estuviese sugeto á cumplir con exactitud

ARC, RA, L 175, E 7, f 8r 
vigilancia sus deberes, y no tuviese motivo de llevarles derechos de vistas ó reproducciones á los Indios, que siendo la única exigüa granjería que tiene el Protector, es gravamen á los Naturales, porque los mas de los litigantes que hay entre ellos son notoriamente pobres, y por eso es que á pesar de mis laboriosas atenciones vivo contrahido á oir y decidir en juicio verbal la mayor parte de las quejas de dichos Indios= Entre estos no hay en el Partido ninguno que tenga las luces y virtudes necesarias al buen desempeño del contenido cargo, á excepción del D[octor] D[on] José Domingo Choqueguanca, quien no ha querido admitir este empleo asegurando, que con brevedad se ha de retirar á continuar con sus estudios en el Cuzco ó Chuquisaca, con cuyo concepto estoy en activa solicitud de una persona que con integridad, pureza, y acierto se contraiga en el contenido ejercicio para efectuar la propuesta con sugecion á lo que V[uestra] S[eñoría] se digne decirme $=$ Dios guarde á V[uestra] S[eñoría] muchos años. Azángaro y noviembre 27 de 1818= Juan Bautista Morales= S[eño]r Gob[ernad]or Intendente D[octor] D[on] Tadeo Joaquin de Garate.

Otra A consecuencia del Oficio de V[uestra] S[eñoría] de 20 del corriente en que me transcribe la solicitud del S[eño]r Fiscal de la Real Audiencia del Distrito sobre los Protectores que hay ó deben haber en cada Partido, debo informar á V[uestra] S[eñoría] que en esta Capital egerce este oficio D[o]n Eusebio Goizueta hacen algunos años sin mas sueldo que el de 4 reales que pagan los litigantes Naturales por cada, y se halla con nombramiento librado por el mismo S[eño]r fiscal. Este es suficiente para este Partido, por residir en la Capital, y hallarse obligado á salir con el Juez territorial á cualquier pueblo, siempre que la necesidad lo exija, con que contesto su citado oficio= Dios guarde á V[uestra] S[eñoría] muchos años. Lampa noviembre 29 de 1818= J[ose]ph Antonio Polotiere $=\mathrm{S}[\mathrm{e}$ ño]r Gob[ernad]or Intendente de la Provincia Don Tadeo Garate.

Otra Diré al Superior Oficio de V[uestra] S[eñoría] de 20 del corriente en que se sirve transcribirme el del S[eño]r D[octo]r D[o]n Martin José Mugica, Ministro fiscal de la Real Audiencia del Cuzco, de 6 del mismo que este Partido no tiene Protector de Naturales: Que entre los Indios no encuentro ninguno capaz de desempeñar tan delicado encargo. De los Españoles, solo D[o]n Mateo Elguera y D[o]n Mariano Bobadilla, me parecen adecuados por su buena conducta y regulares luces; pero creo difícil el que ninguno de ellos se avenga á encargarse de un empleo que no tiene dotacion ninguna, ni otro arbitrio que el de 2 á 4 reales que suelen pagar los Indios por sus escritos á aquellos que en los pueblos se conocen con el nombre de Quelqueres. El Protector en este Partido desde luego sería muy util, si hubiera ramo de que dotarlo, y se encontrase sugeto de conducta, buenas luces y mejores inclinaciones que le hiciera presente á los Naturales su justicia $=$ Dios guarde á V[uestra] S[eñoría] muchos años. Crucero y noviembre 31 de $1818=$ Manuel Antonio de Gomez $=$ S[eño]r Gob[ernad]or Intendente $=$ Es copia. Lampa diciembre 18 de $1818=$ Garate.

Otra Satisfago por ahora al Oficio de V[uestra] S[eñoría] 6 del pasado con la copia adjunta, contestaciones de mis Subdelegados en los cinco Partidos con respecto á los Protectores que deben nombrarse en cada uno de ellos: Y esperando que me individualicen los sugetos capaces de desempeñar tales destinos, y en el entretanto ver la or[de]n que

ARC, RA, L 175, E 7, f 8v 
//F. $9 \mathrm{r} / /$

autorice á V[uestra] S[eñoría] para estos nombramientos en contraposición de la ley, que me faculta, me recervo estenderme s[iemp]re todos y cada uno de los puntos en que se sirve V[uestra] S[eñoría] pedirme le informe= Dios guarde á V[uestra] $\mathrm{S}$ [eñoría] muchos años. Lampa diciembre 18 de $1818=$ Tadeo Garate $=\mathrm{S}[\mathrm{eño}] \mathrm{r}$ fiscal del crimen de la Real Audiencia del Cuzco=

Es copia de las copias y original que quedan en mi poder. Cusco 9, de diciembre de 1819 .

Mugica [rúbrica]

ARC, RA, L 175, E 7, f 9r

[//F. 9v// en blanco] 
//F. 10r//

C.

Copia A pesar de lo prevenido en las Ordenanzas del tit[ulo] 14 lib[ro] $2^{\circ}$. de las de este Reino, mandadas observar por la ley $2^{\mathrm{a}}$. tit[ulo] 6. lib[ro] 6. de la Recopilacion, continúan los desordenes y perjuicios que aquellas procuraron evitar, pues se hacen comunes los Seductores que influyen á los Indios á pleitos, $\mathrm{y}$ fomentan sus discordias con pedimentos que les hacen repetir por los detestables fines de aprovechar el estipendio que por ellos exigen, de hacerles instrumento y órgano de sus venganzas, ó por otros designios igualmente peligrosos que insuperables, resultando de todo la inquietud de los Indios, la separacion de sus familias y hogares, el abandono de sus labores y menoscabo de sus bienes.

Ningun remedio mas eficaz para evitar estos daños y otros de iguales y aun mayores consecuencias, que la observancia del citado tit[ulo] 14, y señaladamente de la Ordenanza $6^{\text {a }}$. de dicho titulo: y asi encargo á V[uestra] $\mathrm{S}$ [eñoría] estrechamente cuide de su cumplimiento, expidiendo las órdenes y providencias conducentes, é imponiendo á los contraventores sin contemplacion, indulgencia, ni disimulo las penas que contra ellos están señaladas.

Dios guarde á V[uestra] S[eñoría] m[ucho]s a[ño]s. Lima 10 de setiembre de 1803= El Marques de Aviles= S[eño]r Presidente Rexente del Cusco=

Cusco y octubre 8 de $1803=$ Acusese el recibo de este Oficio ofreciendo su cumplimiento, y fecho pásese una copia autorisada de él á la Real Audiencia $=$ Una rúbrica $=$ Arechaga .

Es copia de su original: asi lo certifico. Cusco y

ARC, RA, L 175, E 7, f 10r 


\section{Revista Historia y Justicia}

ISSN 0719-4153 revista.historiayjusticia.org N¹0 - Santiago de Chile, abril 2018, p. 241-280

//F. 10v//

octubre 10 de 1803= Mariano de Arechaga=

Es copia exacta de la que corre al n136 tomo $2 .^{\circ}$ del Cedulario de esta Real Audiencia.

Cuzco 9, de diciembre de 1819.

Mugica [rúbrica]

ARC, RA, L 175, E 7, f 10v 
//F. 11r//

$$
\text { M[uy] P[oderoso] S[eñor] }
$$

El fiscal Protector general de los Naturales, vista la contestacion del Partidario de esta ciudad á su consulta 9 de febrero, y lo informado por el S[eño]r Oidor Jues de la Caja de Censos en 6 de marso, dice: Que su continua meditacion en los modos de reanimar el gran número de abatidos, que la Providencia del Señor y la dignacion del Monarca han puesto bajo de su débil clientela, lo ha determinado á hablar y pedir en este expediente mucho mas de lo que se habia propuesto en un principio.

Manda S[u] M[ajestad] en la Real Cédula de 11 de marso de 1781 „que el nombramiento de Protectores Partidarios se verifique solo en los Partidos donde hasta ahora haya sido costumbre haberlos, ó se reconociese urgente necesidad de establecerlos de nuevo, calificada indispensablemente por el Presidente, Regente y Oidores de la Audiencia a quien corresponda."

Por las copias que el fiscal acompaña, marcadas con las letras A y B, verá V[uestra] A[lteza] que en la Provincia del Cusco hay un Protector Partidario en la ciudad, y otro en la Subdelegacion de Paruro; á los cuales deben añadirse el de Paucartambo, y el de la Doctrina de Cotahuasi, cuya existencia ha llegado á entender el fiscal por casualidad, aunque sin conocimiento de sus nominadores ni algun otro

ARC, RA, L 175, E 7, f 11r 
//F. 11v//

especifico y claro: y que en la Provincia de Puno solo tienen ó han tenido Protectores su Capital y los Partidos de Chucuito, Azángaro y Lampa.

La orden que el Virreinato expidió en 10 de setiembre de 803, y que el fiscal presenta en la copia de la letra $\mathrm{C}$, basta por sí sola para convencer la urgente necesidad de establecer Protectores, no solo en todos los Partidos de la comprehension de este Tribunal, mas tambien á ser posible en cada Doctrina; pues á falta de Protector, ó los Indios han de callar los enormes agravios que reciben, no menos en sus domicilios que fuera de ellos, cuyo silencio debe insolentar y multiplicar necesariamente sus ofensores por la misma naturalesa de las cosas; ó los pobres han de salir ordinariamente de sus residencias en busca de pendolistas que bien ó mal les organicen sus quejas, cayendo asi en los inconvenientes que quisieron precaver los Ex[celentísi]mos S[eñores] D[o]n Fran[cis]co Toledo y Marques de Aviles.

Aun cuando fuera posible, que no lo es, someter todos los Indios y todos sus negocios á Juicios puramente verbales; no por eso les serian menos nesesarios en n[uest]ra legislacion actual los Protectores que pudiesen representar y sostener de palabra sus derechos, á causa de los embarazos que tienen los mismos Indios para hacerlo, ya por el servil encogimiento con que se personan y hablan delante de los Jueces, ya por la fastidiosa torpesa con que generalmente se explican, y ya porque muchos y tal ves los mas de los Subdelegados no entienden el idioma de los Indios,

ARC, RA, L 175, E 7, f 11v 
$/ / \mathrm{F} .12 \mathrm{r} / /$

ni sus Interpretes son siempre tan diestros y fieles como sen da [sic: sería] de desear que lo fuesen.

No habiendo de otro lado un pais donde no ocurra con frecuencia que el Indio tenga que testificar, que contratar, que liquidar una cuenta, que otorgar un poder, que intervenir en un deslinde, y que prestarse á otra porcion de iguales actos: ó es menester suspenderle los privilegios de menor, con que $\mathrm{n}$ [uest]ro Derecho y práctica municipal ha tenido y tiene por conveniente agraciarlo; ó situar en todos los lugares donde sea posible el Protector ó Curador legal, que autorice y valide aquellas operaciones.

Se responderá quizá que para tales casos pueden los Jueces echar mano de Protectores provisionales, nombrandolos especialmente para ellos. Pero sobre que cuanto pueda disernirse y decirse contra la institucion y muchedumbre de los Protectores permanentes, otro tanto y algo mas será siempre aplicable á los tales Protectores eventuales y efímeros; un poco de reflexion sobre el corazon del hombre, y otro poco de mundo enseñará á cualquiera, que el Indio ha de merecer precisamente menos consideracion é interes á un Curador casual, precario y las mas veces forsado y repugnante, que no á un Protector titulado, perenne, voluntario y que ha hecho solemne profesion de defenderlo en todo trance.

Mas: el fiscal que quiera desempeñar medianamente su sagrado encargo de Protector, necesita informarse con bastante frecuencia de lo que pasa á los Indios en lo espiritual y temporal, asi

ARC, RA, L 175, E 7, f 12r 


\section{Revista Historia y Justicia}

ISSN 0719-4153 revista.historiayjusticia.org №10 - Santiago de Chile, abril 2018, p. 241-280

$/ / \mathrm{F} .12 \mathrm{v} / /$

en las pequeñas como en las grandes reducciones, y en todos los puntos donde habitaren; ¿y quien será el que le suministre estos informes con tal cual veracidad, desinteres y extension, faltando un Protector subalterno, obligado á darselo por su oficio cada vez que se le pida, é instruido personalmente de los sucesos? ¿Quiénes serán, Señor, estos informantes en unos paises, donde lastimándose casi todos en conversacion de las desgracias del Indio, no pasan acaso de media docena los que en veinte y seis meses han denunciado al fiscal por escrito una ú otra; donde algunos Subdelegados, oficiados políticamente por él para que administrasen justicia á ciertos Indios que interpelaron su ministerio, no han tenido siquiera la dignacion de acusarle el recibo; y donde (lo que aun es mas increíble y vergonzoso) ninguno de los Protectores foráneos se ha servido comunicarle hasta ahora oficial ni epistolarmente que lo sea?

Los inconvenientes experimentados con la antigua supresion de los Protectores y Defensores de los Indios, movieron el Real ánimo de Felipe $2^{\circ}$. á restablecerlos por la ley $1^{\text {a }}$. del tit[ulo] 6 lib[ro] 6 en las Provincias y partes donde los habia: y las verdades que el fiscal acaba de apuntar, con otras mas que pudiera

ARC, RA, L 175, E 7, f 12v 
$/ / \mathrm{F} .13 \mathrm{r} / /$

añadir á no contenerle el miramiento de no cansar demasiado á V[uestra] A[lteza]; verdades notorias entre los conocedores experimentales de la legislacion, práctica forense, costumbres y geografía Americanas, y que por tanto es excusado apoyarlas con documentos y testimonios; estas verdades exigen que durante el presente sistema político con el Indio se aumente todo lo posible el número de sus Protectores.

El fiscal que en largos dos años de egercicio se ha abstenido de nombrar un solo Protector, y de remover a ninguno de los antiguos, manteniendose puramente á la observativa de los hechos y de las personas que no empesar á obrar sin todos los conocimientos que tal cual puedan garantirle el acierto de eleccion; tiene un derecho de esperar que nadie, cuyo voto deba serle importante, lo sospeche tocado de otros afectos que su amor por el crédito de la legislacion territorial y por el bien de los Indios al defender la pluralidad de los Protectores.

Antes que los Subdelegados de la Intendencia de Puno indicasen la total carencia ó escases de hombres á quienes encargar la Protectoría, el fiscal estaba penetrado de ellas cierta ó congeturalmente; pero hoy no se pregunta ¿cuantos sugetos haya capaces de ser Protectores, sino si convengan extenderse estos lo mas

ARC, RA, L 175, E 7, f 13r 
//F. $13 \mathrm{v} / /$

que fuese posible? Decidida afirmativamente esta cuestion, queda al cargo de los fiscales Protectores el buscar las personas idoneas. Sino la encontrasen de una aptitud sublime, quisá las hallarán de una aptitud regular; y cuando ni aun esto pudieren lograr el dia de hoy, acaso le conseguirán en el de mañana: bastando esta posibilidad para que la ley, que siempre tiende la vista á un porvenir indefinido, permita ú ordene con anticipacion su nombramiento. ¿Dejan por ventura de proveerse las Judicaturas, las Plazas de armas, los destinos eclesiasticos y otros empleos públicos, porque no todos los candidatos sean a propósito para ellos? Y si la conservacion del orden no tolera jamas que se prefiera la vacante ó abolicion de ciertos oficios á su provision en funcionarios menos aptos ¿ha de ser mejor el abandonar ó exponer al azar los grandes derechos y privilegios del Indio, que el delegar su celo, custodia y recuperacion á algunas gentes, que si poco hábiles por de pronto, pueden adelantarse con el tiempo, y tambien estimular á otros con sus mismos yerros á hacerse dignos de esta honorífica incumbencia como ha sucedido y sucederá respecto de todas ó las mas instituciones sociales?

La ley de Felipe ya citada, mandando á los fiscales del crimen „que den á los Protectores subalternos las instrucciones y ordenanzas para que conforme á ellas usen y egerzan; y á los Jueces de visitas y residencias y las demas Justicias

ARC, RA, L 175, E 7, f 13v 
$/ / \mathrm{F} .14 \mathrm{r} / /$

Reales, que tengan mucha cuenta y continuo cuidado de mirar como proceden en estos oficios, y castigar con rigor y demostracion los excesos que cometieren": estas celosas prevenciones, á las cuales debe añadirse hoy la vigilancia de los fiscales Protectores sobre sus auxiliares, responde satisfactoriamente á la obgecion de los abusos que pudiera inducir la multitud de Protectores, y que los muchos interesados en perseguir al Indio lejos de atalayas, censores ó respetos que puedan contenerlos, han exagerado y abultarán siempre mas de lo cierto. Señalese un solo plan humano libre de abusos: y sino le hubiere, abandonese el empleo insensato de atacar al respaldo de ellos la plantificacion de los proyectos necesarios ó útiles.

El gran escollo donde tropiesa el actual es ¿cómo se dotan los Protectores particulares? Al hablar el fiscal con V[uestra] A[lteza] en 9 de febrero, opinaba que los Protectores no podian llevar aun los medios derechos de Comunidades y Caciques sin quebrantar la ley $3^{\mathrm{a}}$. de su privativo título; pero habiendo incubado despues profundamente en este punto, halla ser muy probable que la Real Cédula de 781, declarando que los expresados Protectores Partidarios no deben gozar salario alguno por $\underline{\text { rason de sus empleos, }}$ les permite tácitamente en el mismo hecho tirar algunos derechos no solo de las Comunidades, Caciques y Nobles ó Principales, sino es tambien de los Indios comunes que el art[iculo] $4 .^{\circ}$ del exordio y ordenanza $7^{\text {a }}$. tit[ulo] 16

ARC, RA, L 175, E 7, f 14r 


\section{Revista Historia y Justicia}

ISSN 0719-4153 revista.historiayjusticia.org №10 - Santiago de Chile, abril 2018, p. 241-280

//F. $14 \mathrm{v} / /$

lib[ro] $2^{\circ}$. de las del Perú llama Atum-runas, siempre que sean pudientes.

Esta interpretación se funda en que la prohibicion de derechos á los Protectores gira sobre el constante supuesto de que con arreglo á las leyes 3, 4, 8 y 11 del tit[ulo] 6, y á las 8,12 y tres siguientes del tit[ulo] 16 lib[ro] 6, con las cuales guarda exacta conformidad la ordenanza $5^{\mathrm{a}}$. del Perú en los citados título y libro; ellos gozaban de un salario competente y aun aventajado. Luego habiendo tenido por bien Su Magestad suspender á los Protectores todo salario, sin duda por la pobresa á que llegaron en el año 781 los ramos que lo costeaban, y cuya indigencia crece de dia en dia sin que pueda proveerse su término; parece que por consecuencia suspendió tambien, aunque solo implícitamente, la prohibicion legal de pedir y cobrar derechos á los Indios protegidos.

Sino fue esta la intencion Soberana del S[eño]r D[o]n Carlos $3^{\circ}$., por lo menos debe permitirsenos representar á su Augusto Nieto reinante las poderosas rasones que se oponen á la tal prohibicion, ya que no pueda ni deba pensarse hoy en restablecer la antigua dotacion fija de los Protectores subalternos: bien entendido de que si estas rasones convenieren siendo raros los

ARC, RA, L 175, E 7, f 14v 
//F. $15 \mathrm{r} / /$

Protectores, deben convencer por igual aunque sean millares; y por el contrario, como se estimen inadaptables á la hipótesi de muchos Protectores, lo mismo deberán estimarse respecto de pocos, ó mas que sea de uno solo.

Desde luego sería muy de desear que los títulos de Protectores recayesen en Ciudadanos acomodados, que los tomasen y desempeñasen por puro espíritu de religion, humanidad, honor ó mérito; y el fiscal protector esforzarse en buscarlos. Mas ¿cuales y cuantos son los hombres maravillosos, que rodeados de la abundancia y placeres, tengan la heroicidad de renunciarlos ó disminuirlos por enjugar caritativamente las lágrimas agenas que no conocen, y por secar el manantial de ellas á despecho del poder, arbitrariedad y pasiones atrevidas que lo abrieron y lo resguardan? ¿Y cuales y cuantos los que subsistiendo únicamente del sudor de su rostro, quieran derramar de valde mucha parte de el en patrocinar á otros desdichados, y lidiar á braso abierto contra los innumerables encarnizados enemigos de la persona, bienes y toda especie de adelantamiento de estos infortunados?

La ley $4^{\mathrm{a}}$. de los Protectores de Indios se queja de $\mathrm{q}[\mathrm{u}] \mathrm{e}$ ellos y otros cooperadores suyos, nobstante [sic] los aventajados salarios que disfrutaban en la Nueva España, exigían á sus clientes ma-

ARC, RA, L 175, E 7, f 15r 
//F. $15 \mathrm{v} / /$

yores cantidades y presentes, deteniéndolos y retardándolos con mucho agravio y vejacion: y el fiscal no duda que esto mismo sucediese en toda ó la mayor parte de las Americas, porque vive persuadido de que en muy pocas ó ninguna se ha respetado de corazón la voz de los Monarcas en favor del Indio. ¿Cómo pues esperaremos que unos Protectores totalmente indotados se abstengan de pedirle cosa alguna en gratificacion de su trabajo, y que á mas de abstenerse contra toda apariencia, lo despachen con tal cual esmero y brevedad?

El Protector Partidario de esta ciudad confiesa, que algunos Caciques y Comunidades le pagan medios derechos en conformidad á lo que V[uestra] A[lteza] tiene mandado en muchas tasaciones de costas: el fiscal oye rumores de que el Lic[enciado] Yepes cobra tambien poco ó mucho á algunos Indios vulgares; y sin embargo añade Yepes que estos cortos emolumentos nunca se han compensado ni pueden compensar su trabajo continuo, penosas tareas y comprometimientos. El Subdelegado de Azángaro reputa por una granjería exigua los derechos de vistas ó reproducciones que llevaba á los Indios el Protector de su Partido, estimando conveniente que de los bienes de Comunidad se le señalase un salario. Y el de Carabaya cree dificil que ni Elgura ni Bobadilla, únicos de su jurisdiccion capaces de la Protectoría, se avengan á aceptar este empleo que no tiene dota-

ARC, RA, L 175, E 7, f 15v 
$/ / \mathrm{F} .16 \mathrm{r} / /$

cion ninguna, ni otro arbitrio que el de dos á cuatro reales, que suelen pagar los Indios por sus escritos á aquellos que en los pueblos se conocen con el nombre de quellqueres, que significa pendolistas. ¿Qué dirían los Yepes, Morales y Gomes, si se le vedase al primero percibir cosa alguna de sus protegidos, y se le mandase á los otros una nomenclatura de los Protectores que quisieran serlo sin un centavo de sueldo ni pages?

Figurando por un momento que se extinguiesen todos los Protectores, las Justicias se verían precisadas á nombrar Curadores especiales cada ves que el Indio debiese jurar, contratar sobre mayor cuantía, comparecer en juicio, ó intervenir en otros actos que no puede egercer válidamente por sí solo; y el mismo Indio á valerse para sus defensas de algun memorialista práctico, ó Letrado particular. Ni los Curadores especiales, ni los memorialistas servirían graciosamente al Indio, porque la ley no se lo manda; y aun cuando se lo mandase, el fiscal duda que fuese obedecida, porque sabe cuanto repugna al hombre el trabajar á beneficio ageno sin algun interes temporal. Tampoco el Letrado patrocinaría de valde al Indio, no siendo enteramente pobre, y comprehendido como tal en el juramento que hiso al entrar en la carrera, porque la ley 25 tit[ulo] 24 lib[ro] 24 le permite llevar pagar á los Indios, aunque muy moderadas. Tanto es esto, y tal la consideracion dispensada por él Trono á las fatigas del vasallo en esta misma linea, que cuando él

ARC, RA, L 175, E 7, f 16r 


\section{Revista Historia y Justicia}

ISSN 0719-4153 revista.historiayjusticia.org No10 - Santiago de Chile, abril 2018, p. 241-280

//F. 16v//

fiscal tenga que acusar algun Yndio criminal, las Reales Audiencias deben nombrar quien lo defienda, pagandole su honorario de Real Hacienda. Asi lo dispone la Real Cédula de 21 de enero de 792, que aunque el fiscal no la ha visto mas que indicada en unos apuntamientos manuscritos, la jusga efectiva por la seguridad que ha advertido en ellos, sino es que padescan algun equívoco de pluma en esta fecha" [sic]. Pero ¿donde hay rason para que pudiendo y debiendo ser gratificados los que defiendan accidentalmente al Indio en una ú otra ocasión que no les embarasa dedicarse á sus respectivas ocupaciones ó granjerías; no lo hayan de ser los que practican esto mismo por instituto, y con una frecuencia que quita muchisimo tiempo á sus atenciones, industrias y adquisiciones personales?

Que un Indio del todo pobre é insolvente, necesitado de los servicios de su Protector, los reciba sin cargo de remunerarselos con poco ni mucho; solo puede desaprobarlo un corason de bronce, en quien no hagan mella la religion, la humanidad y los mas agudos remordimientos. Pero que un Protector cansado de remar infructuosamente en auxilio de los Indios desnudos, que son los mas y casi todos; tambien haya de sacrificar sin alguna utilidad fisica sus luces,

ARC, RA, L 175, E 7, f 16v 
//F. 17r//

desvelos, pasos, bienes, quietud y puede ser que algo mas, á obsequio de las Comunidad, Caciques, Nobles ó Principales, y aun de algunos plebeyos, quisá tanto ó mas acaudalados que el mismo Protector, solo porque sean Indios: la ley que mandase una cosa semejante pasmaría por su perfeccion á los mismos Cielos, mas por lo mismo dejaría de ser una ley, la cual debe ser convenible á la tierra y al tiempo , como lo dice la $1^{\mathrm{a}}$. tit[ulo] $1^{\circ}$. lib[ro] 2 de la Recopilacion Castellana; y sin lograr nunca su obgeto, solo serviría para hacer en sus infractores otros tantos delincuentes, dar ansa [¿?] á los malos para burlarse igualmente de otras leyes, y traer fluctuando tímidamente á los buenos entre los deseos y la impotencia de obedecer.

Por consecuencia de todo lo rasonado, el fiscal Protector general pide á la autoridad Superior é ilustrada de V[uestra] A[lteza] se sirva declarar interinamente: $1^{\circ}$. Que el fiscal Protector de esta Real Audiencia puede nombrar todos los Protectores auxiliares que tuviere por conveniente, asi en las cabeceras de los Partidos de su distrito, como en cualesquiera otras poblaciones donde su diligencia hallare personas de las calidades conducentes, sin $\mathrm{q}[\mathrm{u}] \mathrm{e}$ tenga la precisión de organizar en cada caso un expediente para

ARC, RA, L 175, E 7, f 17r 


\section{Revista Historia y Justicia}

ISSN 0719-4153 revista.historiayjusticia.org №10 - Santiago de Chile, abril 2018, p. 241-280

//F. $17 \mathrm{v} / /$

probar la necesidad de crear Protector, por ser visible á lo menos en los países sugetos á este Tribunal: $2^{\circ}$. que los tales Protectores subalternos pueden llevar á las Comunidades Caciques, é Indios Principales ó Nobles la mitad de los derechos que por arancel, tasacion ó estilo adeudarían los individuos Españoles en iguales ocurrencias; y á los Indios particulares ó Atun-runas, que no debieren ser reputados pobres de solemnidad, unos derechos que sean y parescan muy moderados atendidas todas las circunstancias de los contribuyentes, negocios, tiempo y trabajo impendido; sobre cuyos dos particulares se encargue á los Protectores estrechísimamente la conciencia, intimandoseles ademas que en ambos casos anoten de su puño con fidelidad y claridad en los respectivos papeles y expedientes las cantidades $\mathrm{q}[\mathrm{u}] \mathrm{e}$ cobrasen, con apercibimiento de que si exedieren de lo permitido en lo mas mínimo, ó se lo pidieren al Indio Atun-runa, pobre en la opinion general, descubierta la verdad breve y sumariamente serán multados y escarmentados sin contemplacion al arbitrio justo y prudente de los Jueces inmediatos ó Superiores: y $3^{\circ}$. que los Protectores subalternos que se desempeñaren en estos encargos con el celo, desinterés y berifica actividad propios de un amante de la religion, leyes y virtudes sociales, contraerán un mérito distinguido y digno de que la Real munificencia y todos los Agentes del Gobierno Español

ARC, RA, L 175, E 7, f 17v 
//F. $18 \mathrm{r} / /$

lo agradezcan y premian singularmente conforme á la carrera y demas aptitudes de los interesados: dignandose V[uestra] A[lteza] por último dar cuenta de estas sus declaraciones interinas al Rey N[uest]ro S[eñ]or en su Real y Supremo Consejo de las Indias con testimonio íntegro del expediente, para la perpetua é inviolable estabilidad de ellas, ó para otras providencias que fueren del Soberano agrado. Cusco 9 de diciembre de $1819=$ Entre r[englone $] \mathrm{s}=$ tasacion ó estilo= vale?

Mugica [rúbrica]

Cusco Dic[iembr]e 14 de 1819.

Corbalan Autos.

Darcourt [dos firmas]

En la Ciudad del Cusco, en catorce dias del mes de Diciembre de mil ochocientos dies y nueve años: Yo el Escribano sobstituto de Camara, hice presente el decreto anterior al Señor Don Martin Joseph de Mugica, del Consejo de su Magestad, Fiscal del crimen de esta real Audiencia, y quedó su Señoria impuesto, estando en su Estudio, de que certifico.

$\mathrm{Cuz}$

ARC, RA, L 175, E 7, f 18r 
//F. $18 \mathrm{v} / /$

co Julio 31 de 1820.

S[eñores] Y vistos en Real Acuerdo ordinario de Justicia con lo expuesto por el Señor Jues Reg[en]te de la Caja de Sensos y pedido por el S[eñ]or Fiscal: mandaron se guarde la Corbalan costumbre y con Testimonio integro por Triplicado del Expediente se dé quenta á Darcourt su Magestad para que se sirba resolber lo que sea de su Soberano agrado sobre los Mosquera particulares que contiene.

[cuatro firmas]

Pedro Joaq[ui]n de Gamarra [rúbrica]

En la Ciudad del Cuzco, en treinta y uno de Julio de mil ochocientos veinte: Yo el Escribano sobstituto de Camara, hice presente el superior auto que antecede al Señor Don Martin Joseph de Mugica del Consejo de su Magestad, y su Fiscal del crimen de esta Real Audiencia, y su Señoria quedó impuesto estando en su Estudio en la casa de su morada, de que certifico.

Gamarra [rúbrica]

ARC, RA, L 175, E 7, f 18v

[Fin] 